\title{
Review \\ Abatacept in the treatment of rheumatoid arthritis
}

\section{Maya $\mathrm{H}$ Buch, Edward M Vital and Paul Emery}

Academic Unit of Musculoskeletal Disease, University of Leeds, Chapeltown Road, Leeds, LS7 4SA, UK

Corresponding author: Paul Emery, p.emery@leeds.ac.uk

Published: 15 October 2008

This article is online at http://arthritis-research.com/supplements/10/S1/S5

(c) 2008 BioMed Central Ltd
Arthritis Research \& Therapy 2008, 10(Suppl 1):S5 (doi:10.1186/ar2416)

universal benefit from TNF- $\alpha$ blocking therapies [11], however, has focused attention on alternative immunological mediators, including T cells.

$\mathrm{T}$-cell biology has regained importance in the pathogenesis of rheumatoid arthritis. Despite the significant improvements associated with the introduction of tumor necrosis factor- $\alpha$ blockade, reasonable proportions of failures and suboptimal responses have been reported, necessitating a search for alternative targeted therapies. This has included drug therapy designed to interrupt T-cell activation via the co-stimulation pathway. Abatacept is a recombinant fusion protein that blocks the co-stimulatory signal mediated by the CD28-CD80/86 pathway, which is required for T-cell activation. Several clinical trials have confirmed the safety and efficacy of this drug in the treatment of rheumatoid arthritis. This review summarizes the clinical data supporting this line of treatment and considers the safety and efficacy data from phase II and III trials.

\section{Introduction}

The role of $T$ cells in rheumatoid arthritis (RA) pathogenesis has regained central importance in recent years. Several observations over the years support a fundamental role for T cells in RA: the association of RA susceptibility with HLA$\mathrm{DR}$ allele on major histocompatibility complex (MHC) class II $[1,2]$; the induction of an inflammatory arthritis by transfer of $\mathrm{CD}^{+} \mathrm{T}$ cells from affected animals into healthy syngeneic recipients [3,4]; and the induction of clinical features of RA in human synovium-severe combined immunodeficient mice [5]. In addition, RA synovium contains a rich infiltrate of activated CD4 ${ }^{+}$cells and $\mathrm{MHC}$ class II [6], with correlation seen between synovial T-cell numbers and severity of joint damage [7].

During the 1990s, the widely accepted concept of cytokine networks perpetuating disease, with tumor necrosis factor (TNF)- $\alpha$ assuming a hierarchical role [8], was supported by the success of TNF- $\alpha$ blocking treatments $[9,10]$. The lack of
The relative lack of success of T-cell-directed therapies stimulated research into alternative methods of targeting T-cell biology, including T-cell co-stimulation; of the multiple co-stimulatory pathways that can upregulate or downregulate T-cell activation, one of the best characterized is that between CD28 and CD80/CD86 (B7 molecules). Both CD80 and CD86 bind to cytotoxic T-lymphocyte antigen (CTLA)4-immunoglobulin (lg) complex (CD152), which shares 30\% homology with CD28 but has a 10 to 20 times greater binding affinity to the B7 molecules [12]. CTLA4 expression and binding therefore competitively inhibit T-cell activation in both naïve and primed $\mathrm{CD}^{+}$and $\mathrm{CD}^{+} \mathrm{T}$ cells, disrupting CD28-dependent T-cell responses [13]. Advances in drug development and protein engineering have facilitated creation of targeted therapies, in this case to interrupt the T-cell-activation pathway. The role of T cells in RA and, in particular, the biology of co-stimulation is the subject of more detailed discussion in other articles included in this supplement. This review concentrates on the outcomes of CTLA4-directed therapies in RA.

\section{Co-stimulation signal blockade}

Abatacept (CTLA4-lg) is a soluble fusion protein that consists of the extracellular domain of human CTLA4 linked to the modified $\mathrm{Fc}$ (hinge, $\mathrm{CH} 2$ and $\mathrm{CH} 3$ regions) portion of human $\operatorname{lgG}_{1}$. Like native CTLA4, the fusion protein binds more avidly to CD80/86 than to CD28. Belatacept (LEA29Y) is a second-generation CTLA4-lg, which is currently in phase III trials in transplantation.

$\mathrm{ACR}=$ American College of Rheumatology; ACR20/ACR50/ACR70 = at least 20\%/50\%/70\% improvement in the American College of Rheumatology criteria for rheumatoid arthritis; AIM = Abatacept in Inadequate responders to Methotrexate; ASSURE = Abatacept Study of Safety in Use with other Rheumatoid arthritis thErapies; ATTAIN = Abatacept Trial in Treatment of Anti-TNF INadequate responders; ATTEST = Abatacept or infliximab versus placebo, a Trial for Tolerability, Efficacy and Safety in Treating RA; CRP = C-reactive protein; CTLA = cytotoxic T-lymphocyte antigen; DAS28 = Disease Activity Score using 28 joint counts; DMARD = disease-modifying antirheumatic drug; EULAR = European League against Rheumatism; $\mathrm{HAQ}=$ Health Assessment Questionnaire; Ig = immunogobulin; IL = interleukin; LDAS = low disease activity scores; LTE = long-term extension; $\mathrm{MHC}=$ major histocompatibility complex; $\mathrm{RA}=$ rheumatoid arthritis; TNF = tumor necrosis factor. 


\section{Therapeutic inhibition with CTLA4-Ig}

A CTLA4-lg fusion protein was initially applied in rodent models of transplantation [14], in which graft survival was prolonged. Subsequent application in nonhuman primate organ transplantation studies, however, was unsuccessful. In contrast, slowing of disease progression was observed in several experimental animal models of autoimmune disease, including lupus and glomerulonephritis [15,16]. CTLA4-Ig prevented development of collagen-induced arthritis if it was administered at the time of immunization, and it ameliorated arthritis if it was given after the onset of disease [17]. Abatacept was therefore developed for application in autoimmune disease, with a number of clinical studies conducted to evaluate its use in RA (the focus of this supplement). To address the poor outcomes in transplantation studies, further development of CTLA4-lg concentrated on improving its binding to CD86 in particular (owing to its importance in initiation of the immune reaction in primates), in order to confer the more potent immunosuppressive action needed. This led to the development of belatacept, a secondgeneration CTLA4-Ig that exhibits superior binding to CD80 and CD86 as compared with the parent CTLA4-Ig.

\section{Abatacept in initial clinical studies}

The cumulative biological and experimental data provided the basis for targeting CD28-mediated T-cell activation in human disease with abatacept. The first clinical study to evaluate the efficacy of abatacept was conducted in patients with psoriasis; $46 \%$ of patients exhibited greater than $50 \%$ sustained improvement in disease activity [18].

\section{Abatacept in rheumatoid arthritis}

Abatacept was subsequently applied in patients with RA. A summary of the clinical efficacy data from each of the main phase II and III trials of abatacept in RA is first presented, followed by cumulative quality of life and safety data.

\section{Phase II studies}

Abatacept monotherapy in patients with rheumatoid arthritis and a history of DMARD failure

An initial dose-ranging study provided preliminary clinical data and has been the only study to assess safety and efficacy of abatacept monotherapy in patients with active RA who had previously failed disease-modifying antirheumatic drug (DMARD) therapy [19]. In this double-blind, placebo-controlled study, patients with $\mathrm{RA}$ received abatacept at $0.5 \mathrm{mg} / \mathrm{kg}$, $2 \mathrm{mg} / \mathrm{kg}$ or $10 \mathrm{mg} / \mathrm{kg}$ doses, or placebo. Infusions were administered at baseline and weeks 2, 4, and 8, with the primary end-point being American College of Rheumatology (ACR) response at 12 weeks. Ninety per cent of the patients were also concurrently receiving prednisolone ( $\leq 10 \mathrm{mg} /$ day). High baseline disease activity, as indicated by high mean tender joint and swollen joint counts (30.3 and 21.9, respectively), was observed. Dose-dependent response to abatacept was seen; $44 \%$ of the $2 \mathrm{mg} / \mathrm{kg}$ group and $53 \%$ of the $10 \mathrm{mg} / \mathrm{kg}$ group achieved the primary outcome of ACR20 (at least 20\% improvement in the ACR criteria for $\mathrm{RA}$ ) response at 12 weeks, as compared with $31 \%$ in the placebo group.

Abatacept plus methotrexate combination in patients with rheumatoid arthritis and a history of DMARD failure

Two key studies provided the initial evidence base for abatacept in combination with methotrexate in patients who have failed DMARD treatment (the second providing 12month data following on from the first study).

The first phase Ilb study compared abatacept in combination with methotrexate versus methotrexate alone in patients with active RA despite at least 6 months of methotrexate treatment (10 to $30 \mathrm{mg} /$ week) [20,21]. All patients exhibited erosive change at baseline with high disease activity, and $90 \%$ of patients were positive for rheumatoid factor. Despite these poor prognostic features and long disease duration (mean 8.9 to 9.7 years for the three treatment groups), it is interesting that only relatively mild functional impairment was recorded (modified Stanford Health Assessment Questionnaire score 1.0 in all treatment groups). A total of 339 patients were randomly assigned to treatment for 6 months with either $2 \mathrm{mg} / \mathrm{kg}(n=105)$ or $10 \mathrm{mg} / \mathrm{kg} \quad(n=115)$ of abatacept, or placebo $(n=119)$; a total of 259 patients (99, 82 and 78 patients in the $10 \mathrm{mg} / \mathrm{kg}, 2 \mathrm{mg} / \mathrm{kg}$, and placebo groups, respectively) completed the study. All patients continued background methotrexate therapy at a mean dose of approximately $15 \mathrm{mg} /$ week. Significantly greater ACR20 responses were seen in the $10 \mathrm{mg} / \mathrm{kg}$ group than in the placebo group (60\% versus 35.3\%) but not with the $2 \mathrm{mg} / \mathrm{kg}$ group (hence only $10 \mathrm{mg} / \mathrm{kg}$ was used in future studies). ACR50 and ACR70 responses were also significantly greater in both abatacept dose groups (Table 1).

In the long-term extension of this phase Ilb study [21] the investigators presented 12-month findings from patients who continued blinded therapy for an additional 6 months, but in this continuation study modification to methotrexate dose with/without change in DMARD was permitted. A total of 90 patients in the $10 \mathrm{mg} / \mathrm{kg}$ abatacept group, 74 in the $2 \mathrm{mg} / \mathrm{kg}$ abatacept group, and 71 in the placebo group completed 1 year of therapy. Similar response rates were observed at 12 months as compared with 6 months, suggesting sustainability of response (Table 1). ACR50 and ACR70 response rates were also greater in the $10 \mathrm{mg} / \mathrm{kg}$ abatacept group than in the placebo group (Table 1). Although rapidity of response with abatacept is slower in comparison with infliximab, high ACR response rates were observed from as early as 30 days, with statistical significance from 90 days. Improvement in response over time has also been suggested to be a feature of abatacept therapy; in this study remission rates (defined as Disease Activity Score using 28 joint counts [DAS28] <2.6) progressively increased over the year in the $10 \mathrm{mg} / \mathrm{kg}$ abatacept group $(34.8 \%$ at 12 months versus $10.1 \%$ in the placebo group; $P<0.001$; Table 1). Low disease activity scores (LDAS; DAS28 <3.2) were similar, 


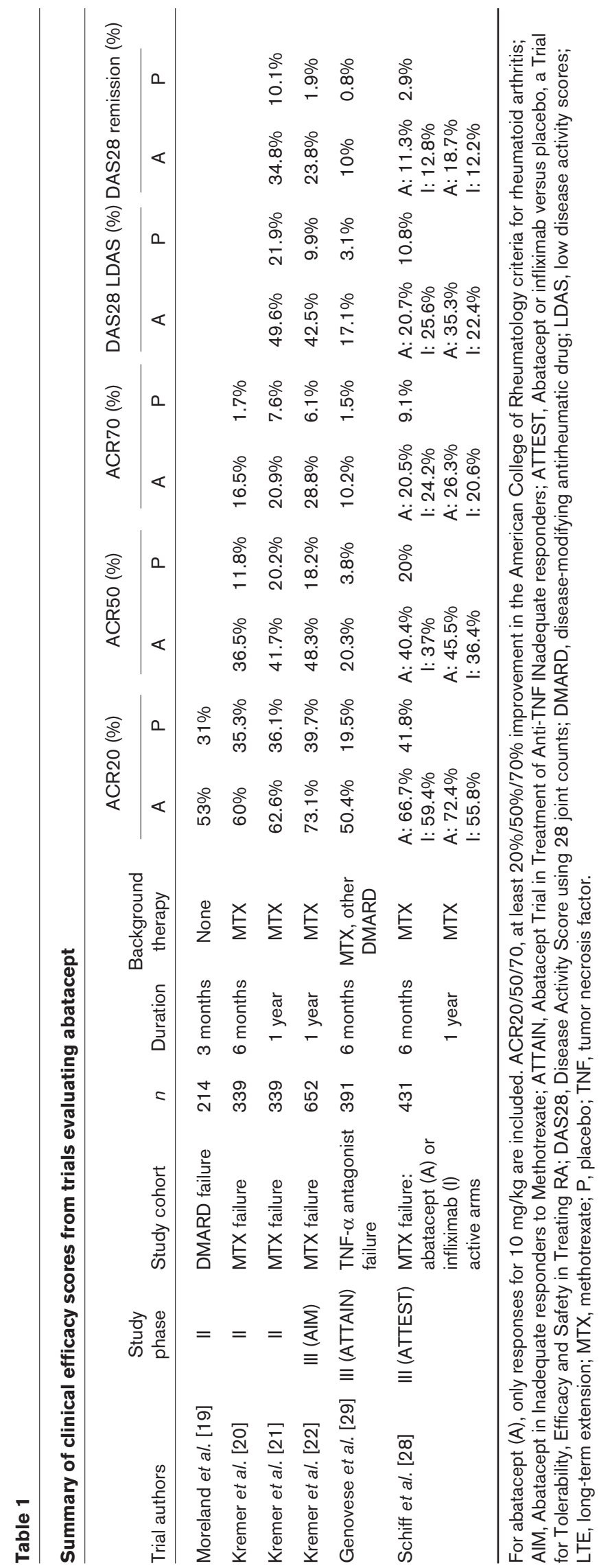

being significantly greater in the $10 \mathrm{mg} / \mathrm{kg}$ abatacept group than in the placebo group. Of the original 115 patients who were treated with abatacept $10 \mathrm{mg} / \mathrm{kg}$ and methotrexate, 75 continued treatment (open label after the blinded portion of study) for a total of 2 years. High ACR50 response rates were maintained $(54.7 \%)$, with an impressive 53\% achieving DAS28 criteria for remission.

It is worth noting that the ability to change DMARDs after 6 months might have influenced the perceived efficacy of abatacept (although patients included had at least failed methotrexate); also, despite long duration of disease, the baseline functional impairment was lower compared with most cohorts, which may lend itself toward greater responsiveness to therapy. Finally, of the original 339 patients randomly assigned to treatment, 235 patients completed the 12-month study (only $n=90$ in the $10 \mathrm{mg} / \mathrm{kg}$ abatacept group).

Abatacept plus etanercept in patients with rheumatoid arthritis and a history of etanercept failure

Combination biologic therapy raises safety concerns, particularly with regard to infection risk. In a 1 year multicentre, randomized, double-blind controlled study [31], an evaluation of the safety and efficacy of abatacept $(2 \mathrm{mg} / \mathrm{kg})$ in combination with etanercept versus placebo and etanercept was undertaken in patients who had failed etanercept (after at least 3 months therapy). No treatment adjustments (including corticosteroids) were allowed until a LTE phase (when those who had received placebo plus etanercept were switched to $10 \mathrm{mg} / \mathrm{kg}$ abatacept). In all, 80/121 patients completed the study (58 in the abatacept plus etanercept arm, and 22 in the placebo plus etanercept arm), with all entering the LTE. Essentially, no significant and meaningful difference in clinical response was observed between these two treatment arms. Safety issues were reported, however (discussed below).

\section{Phase III studies}

Several phase III studies have been undertaken including: the AIM (Abatacept in Inadequate responders to Methotrexate) study evaluated abatacept plus methotrexate in patients failing DMARD treatment; the ATTEST (Abatacept or infliximab versus placebo, a Trial for Tolerability, Efficacy and Safety in Treating RA) study was a comparator study between abatacept and infliximab; the ATTAIN (Abatacept Trial in Treatment of Anti-TNF INadequate responders) study evaluated abatacept plus methotrexate in patients failing TNF$\alpha$ blockade; and the safety study ASSURE (Abatacept Study of Safety in Use with other Rheumatoid arthritis thErapies). The findings of these studies are discussed below.

\section{Abatacept plus methotrexate in patients with rheumatoid} arthritis and a history of DMARD failure (AIM study)

The AIM study sought to evaluate further the safety and efficacy of 1 year of treatment with abatacept (using the $10 \mathrm{mg} / \mathrm{kg}$ dose only) and methotrexate $(n=433)$ as compared with placebo $(n=219)$ and methotrexate in patients with active RA who had 
failed methotrexate treatment (at a dose $\geq 15 \mathrm{mg} /$ week for at least 3 months) [22]. After 6 months, alteration in methotrexate dose, addition of another DMARD, or change in corticosteroid dose ( $\leq 10 \mathrm{mg} /$ day) was permitted. Formal assessment of radiographic outcome was also included in this study (the only clinical trial of abatacept to have radiographic data). Response rates, and radiographic and functional outcomes were all primary end-points. Eighty-nine per cent $(n=385)$ in the abatacept and methotrexate group versus $74 \%(n=162)$ in the placebo group completed the study.

Similar improvements were detected at 6 months, with continued improvement to 1 year. At 1 year, impressive ACR20 response rates were noted in the abatacept group as compared with the placebo group (73.1\% versus $39.7 \%$, respectively). ACR50 and ACR70 responses were also higher in the abatacept group than in the placebo group (Table 1). DAS28 remission was observed in $23.8 \%$ in the abatacept group as compared with $1.9 \%$ in the placebo group at 1 year. The data further suggested that 1-year high response rates (ACR70) were achieved early in study duration; 49\% achieved ACR70 for 6 consecutive months and $21 \%$ for 9 consecutive months. The significant increase in ACR20 response in the abatacept-treated group compared with the placebo group was detected as early as day $15(P=0.008)$; this was mainly driven by patients' and physicians' assessment of disease activity. Specific reference to measures of biological improvement ( $\mathrm{C}$-reactive protein [CRP] reduction) was made; this is in contrast to infliximab and methotrexate studies, in which immediate CRP suppression has been reported [9]. Two-year data from this cohort were also recently reported [23], which demonstrate sustained ACR responses and DAS28 reductions. Specifically, ACR20, 50 and 70 responses of $80.3 \%, 55.6 \%$ and $34.3 \%$ respectively were seen; $56.1 \%$ and $30.9 \%$ of patients in the original abatacept group achieved DAS28 LDAS and DAS28 remission at 2 years.

Radiographic data were available for $92 \%$ of the patients randomized in the study. Different scoring systems exist, including the modified Sharp/van der Heijde score [24] and the Genant-modified Sharp scoring system [25,26]. The latter was employed in this study; it comprises scores at several sites for erosion and joint space narrowing, to give a maximum total Genant-modified Sharp score of 290. The data suggest that over the 1-year period, those patients who received abatacept plus methotrexate progressed at approximately half the rate of patients who were on background placebo plus methotrexate (1.07 units versus 2.4 units, respectively). Although erosion scores also appeared to favor the abatacept treated group, comparable median changes in joint space narrowing and total scores were noted between the groups.

Two-year radiographic data are also now available, which provide information on sustainability (from 467 of the original 652 patients [72\%] randomized who continued on open-label long-term extension [LTE] with abatacept therapy) [27]. For those patients who had been on placebo and were switched to abatacept, the rate of progression was considerably diminished (from 2.4 units at 1 year to only 3.1 at the end of the second year). Similarly, for those patients who completed 2 years on abatacept, impressive retardation in radiographic progression was seen in the second year (essentially half the progression seen in the first year, with 1.07 units in year 1 to a total of 1.5 units in the second year). These data imply reduction in structural damage over time, with the suggestion that improvements in the second year appear to be better even than those in the first year. Comparable data on radiographic progression in abatacept-treated nonresponders (as seen in infliximab-treated patients) were not directly reported. The recent report also confirmed further inhibition of radiographic progression during year 2 [23].

\section{Abatacept or infliximab plus methotrexate in patients with rheumatoid arthritis and a history of DMARD failure (ATTEST study)}

The more recent 'ATTEST' study (Abatacept or infliximab versus placebo, a Trial for Tolerability, Efficacy and Safety in Treating RA) was a comparator trial that compared abatacept ( $n=156)$, infliximab $(n=165)$, and placebo $(n=110$; plus background methotrexate) in a 1-year efficacy and safety trial conducted in 431 patients with RA who had previously failed methotrexate ( $\geq 15 \mathrm{mg} /$ week) [28]. The study design was not powered to distinguish between the effects of abatacept and those of infliximab. After day 197, adjustments in DMARD (including methotrexate dose with/without addition of other DMARDs), corticosteroid ( $\leq 10 \mathrm{mg} /$ day), or nonsteroidal antiinflammatory drug use was permitted. After 6 months, placebo-treated patients could switch to abatacept. At 6 months, DAS28 improvements, European League against Rheumatism (EULAR) responses, and ACR response rates were all significantly better in the abatacept and infliximab groups than in the placebo group (Table 1). Interestingly, there were suggestions of greater ACR and EULAR responses, and greater LDAS and DAS28 (erythrocyte sedimentation rate) remission rates in the abatacept group than in the infliximab group, and a more durable response in the abatacept group, although it should be noted that in the infliximab group only the $3 \mathrm{mg} / \mathrm{kg}$ dose was used (with no opportunity to dose escalate). Nevertheless, the efficacy of abatacept and infliximab relative to placebo appeared comparable, with both being reasonable options within the context of DMARD failure. (Safety profiles are discussed below.)

Abatacept plus methotrexate in patients with rheumatoid arthritis and a history of TNF- $\alpha$ blockade failure (ATTAIN study) Application of alternatively targeted therapies within the context of TNF- $\alpha$ blockade failure in RA formed the basis for the ATTAIN study [29], which was a multicentre, randomized, placebo-controlled study comparing abatacept (approximating $10 \mathrm{mg} / \mathrm{kg}$ ) with placebo. Patients included had 
exhibited inefficacy (not toxicity) to a TNF- $\alpha$ antagonist. Sixmonth ACR20 response and Health Assessment Questionnaire (HAQ) disability index improvement of at least 0.3 formed the two primary end-points. Totals of 258 and 133 patients were randomly assigned to receive abatacept and placebo, respectively, in addition to background DMARD therapy. More than $70 \%$ of patients were seropositive and more than $75 \%$ of patients in each group were receiving background methotrexate. The majority of patients had failed infliximab treatment $(>60 \%$ in each group), with the rest being essentially etanercept failures $(>30 \%)$, because use of adalimumab was not as widespread at the time of enrolment.

A total of 223/258 and 99/133 patients randomly assigned to receive abatacept and placebo, respectively, completed the study. At 6 months, significantly greater ACR20, ACR50, and ACR70 response rates were seen in the abatacepttreated group (ACR20 response rate 50.4\%) as compared with the placebo group (19.5\%; Table 1). A higher proportion of abatacept-treated patients achieved DAS28 LDA as well as DAS28 remission at 6 months compared with placebo $(P<0.001$; Table 1); achieving such endpoints is impressive in this particularly resistant cohort.

Subsequent to the 6-month double-blind study, an 18-month open-label, LTE treatment with abatacept was reported [30], which allowed sustainability of response (over 24 months) to be examined. It confirmed durability of response in this refractory group of patients. In patients originally randomly assigned to abatacept, ACR responses (ACR20, ACR50, and ACR70) were all maintained, with 6-month and 2-year ACR20 responses of $59.4 \%$ and $56.2 \%$, respectively. These data illustrate that abatacept is an attractive option in the challenging group of patients who are resistant to TNF- $\alpha$ blockade.

\section{Function and quality of life}

Function and quality of life assessment is a key component of overall evaluation of therapeutic success; the aim of clinically effective interventions is to reduce the burden of disease on quality of life and impact on health outcomes. The trials evaluating abatacept described above have all included quality of life measures. The quality of life benefit has been a particularly impressive feature of abatacept therapy.

\section{Function}

Improvement in modified $\mathrm{HAQ}$ (reported in the phase II trial [21] as well as in the AIM study [22]) has been detected as early as 30 days [21]. Two-year and 3-year patient data have also confirmed sustained response in modified HAQ (49.3\% at 3 years), with significant improvement in physical function also observed [32]. Functional improvement is difficult to achieve in the challenging TNF- $\alpha$-refractory group by virtue of probable secondary damage that would be incurred; the ATTAIN study is notable for the statistically greater benefits in physical function (defined by improvement in HAQ-Disability
Index of at least 0.3) seen (by day 15) in the abatacepttreated group, which was sustained at 2 years $[29,30]$.

Quality of life (36-item Short Form)

Studies of abatacept have all generally confirmed improvements in quality of life measures (including all domains and summary scores of the 36-item Short Form), with sustained physical and mental component scores in the LTE arm [20,21]. The AIM study [22] also demonstrated significant improvements in the same outcomes in the abatacept group, which were maintained at 1 year. A recent report included a comprehensive assessment of health-related quality of life domains and confirmed positive effects [32].

Figures 1 and 2 and Table 2 detail the quality of life and functional outcomes reported from the AIM and ATTAIN studies respectively [32] and [33].

\section{Safety}

Abatacept with nonbiologic/biologic DMARDs and co-morbidities

The ASSURE study was a 1-year, multicentre, double-blind, placebo-controlled trial with safety as its end-point [34]. A total of 1,441 patients with a wide range of co-morbidities, including diabetes mellitus (7\%), asthma (6\%), chronic obstructive pulmonary disease (4\%), and congestive heart failure (1\%), were recruited and randomly assigned to either receive abatacept or placebo, both in combination with oral DMARDs, anti-TNF- $\alpha$, or anti-IL- 1 biologic agents. The safety data for abatacept in combination with nonbiologic DMARDs were comparable to those from other trials. Patients with chronic obstructive pulmonary disease experienced more frequent exacerbations on abatacept. Abatacept in combination with biologic agents, however, did not appear to be safe, with increased incidence of serious infection and neoplasm; hence, this combination is not recommended [34]. The combination abatacept-etanercept study described above [31] confirmed this poor safety profile. Table 3 summarizes data from the ASSURE study.

The various trials discussed above confirmed the reassuring safety profile of abatacept, with nasopharyngitis, headache, and nausea being the most frequently reported adverse events. The initial phase II/LTE study actually reported fewer serious adverse events and a lower discontinuation rate in the $10 \mathrm{mg} / \mathrm{kg}$ abatacept group than in the $2 \mathrm{mg} / \mathrm{kg}$ abatacept and placebo groups. In the AIM study [22], adverse events led to more discontinuations in the abatacept group than in the placebo group $(4.2 \%$ versus $1.8 \%)$. Although the incidence of serious adverse events was greater in the abatacept group (mainly hospitalization due to disease flare or elective surgery), the rate of discontinuation because of serious adverse events was similar in both abatacept and placebo groups. Increased incidence of infection, with more cases of pneumonia, was noted in the abatacept group. Two deaths (one in each treatment arm) were observed (aspergillo- 


\section{Figure 1}

(a)

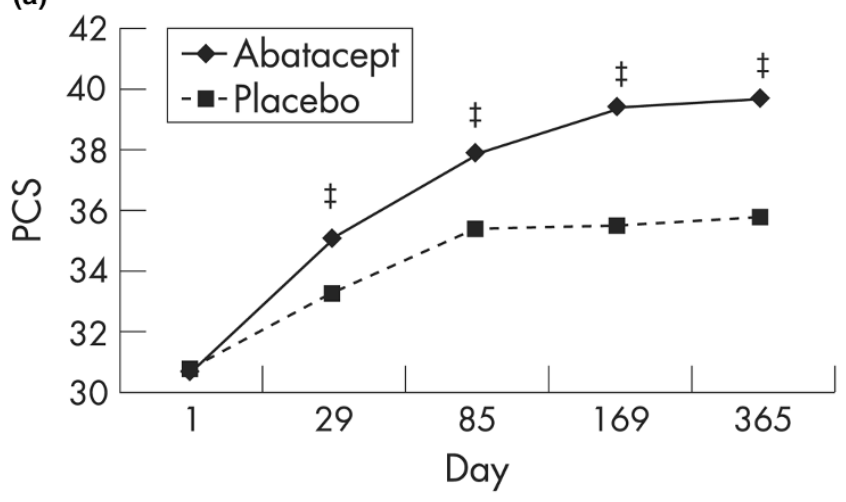

(b)

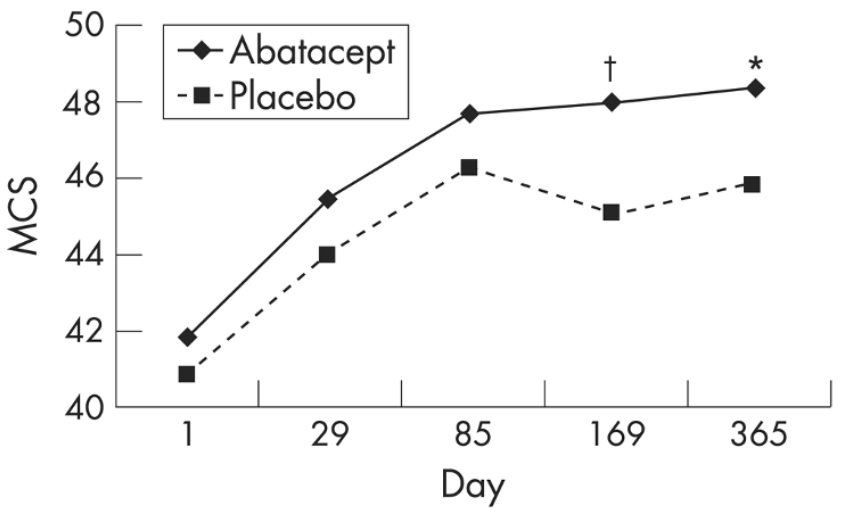

Mean SF-36 (a) physical (PCS) and (b) mental (MCS) component summary score by treatment group and visit $\left({ }^{\star} P<0.05 ;{ }^{\dagger} P<0.01\right.$; $\left.{ }^{\ddagger} P<0.001\right)$. Treatment groups are 'Abatacept' $=$ abatacept + MTX and 'Placebo' = placebo + MTX. Reproduced from Ann Rheum Dis 2007, 66:189-194 [32] with permission from the BMJ Publishing Group.

sis and Pseudomonas aeruginosa infection in one patient, and $P$. aeruginosa infection in the second). In the ATTAIN study [29] similar rates of discontinuation because of adverse events and serious adverse events, and similar incidences of serious infections were noted in the abatacept-treated and placebo groups; these findings were corroborated by LTE rates. The ATTEST trial study design allowed for comparison between the two active treatments (abatacept and infliximab) at 1 year. A higher rate of acute infusional reactions was seen in the infliximab group versus abatacept group, 24.8 versus $7.1 \%$, respectively [28]. Serious infections were fewer in the abatacept group (1.3\%) than in the placebo $(2.7 \%)$ and infliximab (4.2\%) groups.

\section{Malignancy}

The initial phase III/LTE study [21] included one case of bladder cancer, two cases of basal cell carcinoma and one neoplasm in the $10 \mathrm{mg} / \mathrm{kg}$ abatacept group, and one case each of endometrial cancer, squamous cell carcinoma and malignant melanoma in the placebo group. Comparable inci-
Figure 2

(a)
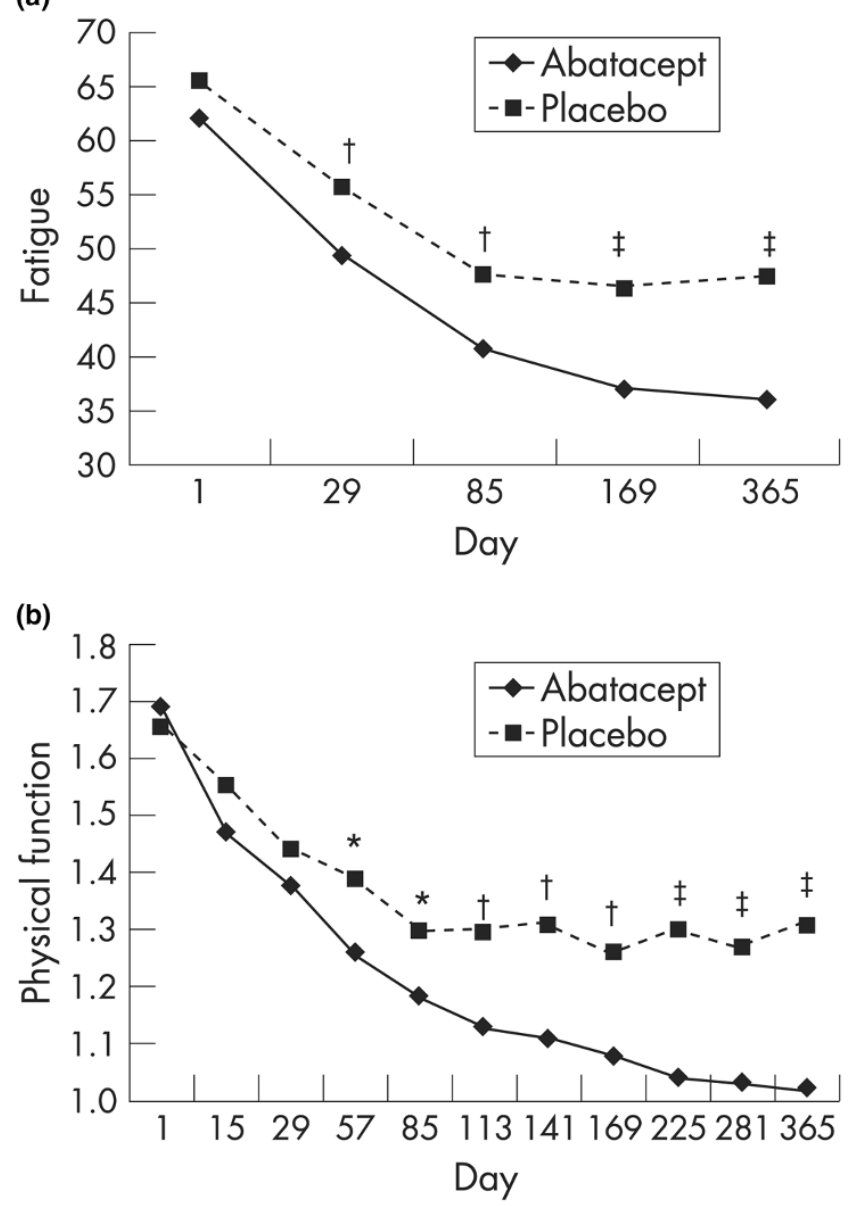

Mean (a) Fatigue VAS score and (b) HAQ-DI score by treatment group and visit $\left({ }^{\star} P<0.05 ;{ }^{\dagger} P<0.01 ;{ }^{\ddagger} P<0.001\right)$. Treatment groups are 'Abatacept' $=$ abatacept + MTX and 'Placebo' $=$ placebo + MTX. Reproduced from Ann Rheum Dis 2007, 66:189-194 [32] with permission from the BMJ Publishing Group.

dences of malignancy in both treatment groups in the AIM study [22] were observed and included a large B-cell lymphoma of thyroid (on a background of Hashimoto's thyroid) in the abatacept group as well as a case of endometrial cancer in the placebo group. The ATTAIN [29] study identified 11 neoplasms during the 2-year period; five out of 11 were nonmelanomatous skin cancers as well as a T-cell lymphoma.

\section{Autoimmune disorders}

Biologic agents have been associated with development of alternative autoimmune disorders (for example, there is a suggestion of lupus syndromes in patients treated with TNF- $\alpha$ blockade [35] and psoriasis in those undergoing treatment with rituximab [36]). Reports of new disease have been reported in abatacept-treated patients, although no specific association has been found. In the ATTAIN study [30], 15 cases of autoimmune disorders were reported; these inclu- 


\begin{tabular}{|c|c|c|c|}
\hline & $\begin{array}{c}\text { Abatacept } \\
\text { (mean change } \\
\text { from baseline) }\end{array}$ & $\begin{array}{c}\text { Placebo } \\
\text { (mean change } \\
\text { from baseline) }\end{array}$ & $\begin{array}{c}P \text { value } \\
\text { (abatacept versus } \\
\text { placebo) }\end{array}$ \\
\hline Physical functioning & 5.3 & 1.2 & 0.0001 \\
\hline Physical role & 6.7 & 0.8 & $<0.0001$ \\
\hline Pain & 8.7 & 2.2 & $<0.0001$ \\
\hline General health & 3.9 & 0.7 & 0.0002 \\
\hline Vitality & 6.9 & 1.2 & $<0.0001$ \\
\hline Social functioning & 7.4 & 2.2 & $<0.0001$ \\
\hline Emotional role & 6.3 & 2.0 & 0.0133 \\
\hline Mental health & 4.6 & 1.1 & 0.0012 \\
\hline Physical component score & 6.5 & 1.0 & $<0.0001$ \\
\hline Mental component score & 5.5 & 1.7 & 0.0025 \\
\hline Fatigue VAS & -22.1 & -5.3 & $<0.0001$ \\
\hline
\end{tabular}

Quality of life components are shown from the ATTAIN study, which compared abatacept plus methotrexate versus placebo plus methotrexate in patients with rheumatoid arthritis who were refractory to tumor necrosis factor- $\alpha$ inhibition. ATTAIN, Abatacept Trial in Treatment of Anti-TNF Inadequate Responders; MOS, medical outcome study; VAS, visual analog score.

Table 3

\begin{tabular}{|c|c|c|c|c|}
\hline Number of events (\%) & $\begin{array}{l}\text { Abatacept plus } \\
\text { nonbiologic } \\
\text { DMARD } \\
(n=856)\end{array}$ & $\begin{array}{c}\text { Placebo plus } \\
\text { nonbiologic } \\
\text { DMARD } \\
(n=418)\end{array}$ & $\begin{array}{c}\text { Abatacept plus } \\
\text { biologic } \\
\text { DMARD } \\
(n=103)\end{array}$ & $\begin{array}{c}\text { Placebo plus } \\
\text { biologic } \\
\text { DMARD } \\
(n=64)\end{array}$ \\
\hline Death & $5(0.6)$ & $4(1.0)$ & 0 & 0 \\
\hline Total adverse events & $768(89.7)$ & $360(86.1)$ & $98(95.1)$ & $57(89.1)$ \\
\hline Serious adverse events & $100(11.7)$ & $51(12.2)$ & $23(22.3)$ & $8(12.5)$ \\
\hline Discontinuations because of adverse events & $43(5.0)$ & $18(4.3)$ & $9(8.7)$ & $2(3.1)$ \\
\hline Serious infection & $22(2.6)$ & $7(1.7)$ & $6(5.8)$ & $1(1.6)$ \\
\hline Neoplasm (benign/malignant) & $27(3.2)$ & $16(3.8)$ & $7(6.8)$ & $1(1.6)$ \\
\hline
\end{tabular}

Number (\%) of events are included for abatacept and placebo in combination with either nonbiologic DMARD or biologic DMARD at 1 year. ASSURE, Abatacept Study of Safety in Use with other Rheumatoid arthritis thErapies; DMARD, disease-modifying antirheumatic drug.

ded three cases of psoriasis and two patients with vasculitis. Four of the cases were observed in the double-blind period and 11 cases during 18 months of open-label treatment.

\section{Infusion reactions}

Abatacept infusions are administered relatively rapidly (over 30 minutes), with generally reassuring tolerability. A lower incidence of acute infusion reactions was observed in the abatacept group as compared with the placebo and infliixmab groups in the ATTEST study [28] (5.1\%, 10.0\% and 18.2\%, respectively). The AIM study [22] reported more acute and peri-infusional infusion reactions with abatacept than with placebo, with two patients discontinuing because of severe acute infusion reactions. One patient experienced hypersensitivity (rash and chest pain) after the second infusion; the second patient experienced severe hypotension during the fourth infusion. Mild-to-moderate acute infusion reactions were slightly more common in the abatacept-treated group $(5 \%)$ than in the placebo group $(3 \%)$ in the ATTAIN study, although no severe reactions were observed.

\section{Immunogenicity}

Immunogenicity studies, conducted as part of the previously discussed trials, did not demonstrate significant production of anti-abatacept antibodies, which is in keeping with the properties and advantages of a fully humanized fusion 
protein. Specifically, the monotherapy study [19] did not identify antibodies to abatacept. In the combination with LTE study [21], most patients had pre-existing antibodies against CTLA4. Two patients produced antibodies against the CTLA4-T portion (not the whole molecule), which were transient in one and there was no follow up in the second. Six patients (1.4\%) in the AIM study exhibited antibody reactivity to abatacept. The pattern of ACR2O responses in these patients with anti-CTLA4 antibodies was unchanged, with no evidence of a hypersensitivity reaction. In the larger, phase III trial [29] antibodies against abatacept developed in 1.3\% of patients and were of low reactivity. More recent reporting of immunogenicity in the phase II and III trials using direct form enzyme-linked immunosorbent assay (more sensitive for the phase III study) [37] confirmed these findings, with a minimum of sequelae. Significant seroconversion for anti-nuclear antibodies has not been noted; in the ATTAIN study [29] antinuclear antibodies were detected in $7.5 \%$ of patients in the abatacept group and $11.3 \%$ in the placebo group.

A recent report [38] summarized the safety findings by way of an integrated safety analysis of five randomized, placebocontrolled, double-blind, core abatacept clinical trials, generating 4,764 patient-years of exposure in total. Continued follow up will establish whether the current acceptable safety profile is maintained with long-term abatacept use.

\section{Mechanism of action studies}

In vitro and in vivo studies have demonstrated inhibition of immune responses by CTLA4-Ig molecules, with downregulation of $\mathrm{T}$-cell proliferation and inhibition of humoral immune response [39]. Inhibition of the proliferation of both circulating naïve and memory T cells has been observed [40], which may assist in reducing the number of activated autoreactive $T$ cells available for entry into the synovium. Other studies have shown reduction in proinflammatory cytokine production by antigen-presenting cells when synovial cells were co-cultured with CTLA4-lg [41]. Evaluation of biomarkers in patients recruited as part of the AIM and ATTAIN studies confirmed an effective cellular action [42]; specifically, reductions in rheumatoid factor, CRP, soluble IL-2 receptor, IL-6, TNF- $\alpha$, E-selectin, soluble intercellular adhesion molecule-1, and matrix metalloproteinase III were observed. T-cell proliferation studies demonstrated marked inhibition when stimulated by dendritic cells, although this effect was less pronounced with $B$ cells as the antigenpresenting cell [43].

A first mechanistic study employed dynamic contrast-enhanced magnetic resonance imaging in combination with synovial histology and gene expression techniques to determine the effect of abatacept on the synovium of patients with RA failing TNF- $\alpha$ blockade [44]. A modest (nonsignificant) reduction in synovial infiltrate was observed within the context of a generalized reduction in proinflammatory gene expression,

\section{Key messages}

- Lack of success of T-cell-directed therapies has stimulated research into targeting T-cell costimulation.

- CTLA4-Ig competitively inhibits T-cell activation through its greater binding affinity to the B7 molecules.

- Abatacept is a soluble fusion protein that comprises the extracellular domain of human CTLA4 linked to the modified Fc portion of human $\lg _{1}$.

- Clinical trials have demonstrated abatacept to be efficacious in patients with RA who have failed previous DMARDs with radiographic benefit shown in MTX refractory study population.

- Trials have also shown abatacept to be an effective option in patients who are refractory to TNF- $\alpha$ inhibition with impressive quality of life improvements.

- Future strategies are likely to evaluate abatacept in early disease.

particularly interferon- $\gamma$; these findings were complemented by reduced synovial volume, as indicated by magnetic resonance imaging. These data are in contrast to the dramatic de-populating effect on the synovium observed with TNF- $\alpha$ blocking agents $[45,46]$, and suggest a greater deactivating effect on the synovium (consistent with an immunomodulatory effect of T-cell co-stimulation therapy).

\section{Conclusion}

The introduction of abatacept, the first T-cell co-stimulation blocking therapy, has added to the growing armamentarium of targeted therapies for the management of RA. It is clear that abatacept is a safe and efficacious option for RA treatment, including in the challenging group of patients who are refractory to TNF- $\alpha$ blockade. It remains to be seen where exactly abatacept will fit in with the rest of the biologic and emerging therapies; emerging therapies; currently in the UK and Europe, failure to respond to TNF- $\alpha$ blockade remains the main application. The impressive and similar response rates in TNF- $\alpha$ blockade failures to those observed in only DMARD failure (included in the phase Ilb trial) implies that the pathways that are targeted with the two treatments remain distinct (contrasting with observations seen using IL-1-directed therapy in patients failing TNF- $\alpha$ blockade, which suggested that TNF$\alpha$ blockade failure predicts IL-1 blockade failure) [47].

Future applications of T-cell co-stimulation blockade are likely to include its evaluation early in disease; the possibility of 
achieving drug-free remission with such an agent is an exciting prospect. Use of abatacept in other autoimmune diseases is also under investigation, including in active lupus nephritis, with increasing evidence arguing for a clinical trial [48]. The suboptimal results observed in transplantation, in particular, have led to the development of belatacept. The latter is a second-generation CTLA4-Ig that exhibits superior binding to CD80 and CD86 compared with CTLA4-lg, thereby having more potent immunosuppressive properties, as are required for transplantation [49].

To conclude, abatacept represents the first clinical application of co-stimulation blockade in RA. Its proven success in RA will encourage its use in other disease groups and will allow refinement of approaches to targeting the T-cell pathway in specific microenvironments.

\section{Competing interests}

PE provides clinical trials and expert advice to Bristol-Myers Squibb. MHB and EMV declare that they have no competing interests.

\section{Acknowledgements}

This article is published as part of Arthritis Research \& Therapy Volume 10 Supplement 1, 2008: Co-stimulation blockade: from bench to bedside. The full contents of the supplement are available online at http://arthritis-research.com/supplements/10/S1.

Publication of this supplement has been sponsored by Bristol-Myers Squibb Company.

\section{References}

1. Calin A, Elswood J, Klouda PT: Destructive arthritis, rheumatoid factor, and HLA-DR4. Susceptibility versus severity, a casecontrol study. Arthritis Rheum 1989, 32:1221-1225.

2. Winchester R: The molecular basis of susceptibility to rheumatoid arthritis. Adv Immunol 1994, 56:389-466.

3. Banerjee S, Webber C, Poole AR: The induction of arthritis in mice by the cartilage proteoglycan aggrecan: roles of $\mathrm{CD}^{+}$ and CD8 ${ }^{+}$T cells. Cell Immunol 1992, 144:347-357.

4. Breedveld FC, Dynesius-Trentham R, de Sousa M, Trentham DE: Collagen arthritis in the rat is initiated by $C D 4^{+} T$ cells and can be amplified by iron. Cell Immunol 1989, 121:1-12.

5. Mima T, Saeki Y, Ohshima S, Nishimoto N, Matsushita M, Shimizu M, Kobayashi Y, Nomura T, Kishimoto T: Transfer of rheumatoid arthritis into severe combined immunodeficient mice. The pathogenetic implications of $\mathrm{T}$ cell populations oligoclonally expanding in the rheumatoid joints. $J$ Clin Invest 1995, 96: 1746-1758.

6. Van Boxel JA, Paget SA: Predominantly T-cell infiltrate in rheumatoid synovial membranes. $N$ Engl J Med 1975, 293: 517-520.

7. Kraan MC, Haringman JJ, Weedon H, Barg EC, Smith MD, Ahern MJ, Smeets TJ, Breedveld FC, Tak PP: T cells, fibroblast-like synoviocytes, and granzyme $\mathrm{B}^{+}$cytotoxic cells are associated with joint damage in patients with recent onset rheumatoid arthritis. Ann Rheum Dis 2004, 63:483-488.

8. Feldmann M, Brennan FM, Maini RN: Role of cytokines in rheumatoid arthritis. Annu Rev Immunol 1996, 14:397-440.

9. Maini R, St Clair EW, Breedveld F, Furst D, Kalden J, Weisman M, Smolen J, Emery P, Harriman G, Feldmann M, Lipsky P: Infliximab (chimeric anti-tumour necrosis factor alpha monoclonal antibody) versus placebo in rheumatoid arthritis patients receiving concomitant methotrexate: a randomised phase III trial. ATTRACT Study Group. Lancet 1999, 354:1932-1939.

10. Moreland LW, Baumgartner SW, Schiff MH, Tindall EA, Fleischmann RM, Weaver AL, Ettlinger RE, Cohen S, Koopman WJ,
Mohler K, Widmer MB, Blosch CM: Treatment of rheumatoid arthritis with a recombinant human tumor necrosis factor receptor (p75)-Fc fusion protein. N Engl J Med 1997, 337:141147.

11. Lipsky PE, van der Heijde DM, St Clair EW, Furst DE, Breedveld FC, Kalden JR, Smolen JS, Weisman M, Emery P, Feldmann M, Harriman GR, Maini RN; Anti-Tumor Necrosis Factor Trial in Rheumatoid Arthritis with Concomitant Therapy Study Group: Infliximab and methotrexate in the treatment of rheumatoid arthritis. Anti-Tumor Necrosis Factor Trial in Rheumatoid Arthritis with Concomitant Therapy Study Group. N Engl J Med 2000, 343:1594-1602.

12. Linsley PS, Brady W, Urnes M, Grosmaire LS, Damle NK, Ledbetter JA: CTLA-4 is a second receptor for the B cell activation antigen B7. J Exp Med 1991, 174:561-569.

13. Alegre ML, Frauwirth KA, Thompson CB: T-cell regulation by CD28 and CTLA-4. Nat Rev Immunol 2001, 1:220-228.

14. Lenschow DJ, Zeng Y, Thistlethwaite JR, Montag A, Brady W, Gibson MG, Linsley PS, Bluestone JA: Long-term survival of xenogeneic pancreatic islet grafts induced by CTLA4Ig. Science 1992, 257:789-792.

15. Finck BK, Linsley PS, Wofsy D: Treatment of murine lupus with CTLA4Ig. Science 1994, 265:1225-1227.

16. Reynolds J, Tam FW, Chandraker A, Smith J, Karkar AM, Cross J, Peach R, Sayegh MH, Pusey CD: CD28-B7 blockade prevents the development of experimental autoimmune glomerulonephritis. J Clin Invest 2000, 105:643-651.

17. Webb LM, Walmsley MJ, Feldmann M: Prevention and amelioration of collagen-induced arthritis by blockade of the CD28 costimulatory pathway: requirement for both B7-1 and B7-2. Eur $\mathrm{J}$ Immunol 1996, 26:2320-2328.

18. Abrams JR, Lebwohl MG, Guzzo CA, Jegasothy BV, Goldfarb MT, Goffe BS, Menter A, Lowe NJ, Krueger G, Brown MJ, Weiner RS, Birkhofer MJ, Warner GL, Berry KK, Linsley PS, Krueger JG, Ochs HD, Kelley SL, Kang S: CTLA4Ig-mediated blockade of T-cell costimulation in patients with psoriasis vulgaris. J Clin Invest 1999, 103:1243-1252.

19. Moreland LW, Alten R, Van den Bosch F, Appelboom T, Leon M, Emery P, Cohen S, Luggen M, Shergy W, Nuamah I, Becker JC: Costimulatory blockade in patients with rheumatoid arthritis: a pilot, dose-finding, double-blind, placebo-controlled clinical trial evaluating CTLA-4Ig and LEA29Y eighty-five days after the first infusion. Arthritis Rheum 2002, 46:1470-1479.

20. Kremer JM, Westhovens R, Leon M, Di Giorgio E, Alten R, Steinfeld S, Russell A, Dougados M, Emery P, Nuamah IF, Williams GR, Becker JC, Hagerty DT, Moreland LW: Treatment of rheumatoid arthritis by selective inhibition of T-cell activation with fusion protein CTLA4lg. N Engl J Med 2003, 349:19071915.

21. Kremer JM, Dougados M, Emery P, Durez P, Sibilia J, Shergy W, Steinfeld S, Tindall E, Becker JC, Li T, Nuamah IF, Aranda R, Moreland LW: Treatment of rheumatoid arthritis with the selective costimulation modulator abatacept: twelve-month results of a phase iib, double-blind, randomized, placebo-controlled trial. Arthritis Rheum 2005, 52:2263-2271.

22. Kremer JM, Genant HK, Moreland LW, Russell AS, Emery P, Abud-Mendoza C, Szechinski J, Li T, Ge Z, Becker JC, Westhovens R: Effects of abatacept in patients with methotrexateresistant active rheumatoid arthritis: a randomized trial. Ann Intern Med 2006, 144:865-876.

23. Kremer JM, Genant HK, Moreland LW, Russell AS, Emery $P$, Abud-Mendoza C, Szechinski J, Li T, Teng J, Becker JC, Westhovens R: Results of a two-year followup study of patients with rheumatoid arthritis who received a combination of abatacept and methotrexate. Arthritis Rheum 2008, 58:953-963.

24. van der Heijde DM, van Riel PL, Nuver-Zwart IH, van de Putte LB: Sulphasalazine versus hydroxychloroquine in rheumatoid arthritis: 3-year follow-up. Lancet 1990, 335:539.

25. Genant HK: Methods of assessing radiographic change in rheumatoid arthritis. Am J Med 1983, 75:35-47.

26. Genant HK, Jiang Y, Peterfy C, Lu Y, Redei J, Countryman PJ: Assessment of rheumatoid arthritis using a modified scoring method on digitized and original radiographs. Arthritis Rheum 1998, 41:1583-1590.

27. Genant HK, Peterfy CG, Westhovens R, Becker JC, Aranda R, Vratsanos G, Teng J, Kremer JM: Abatacept inhibits structural damage progression in rheumatoid arthritis: results from the 
long-term extension of the AIM trial. Ann Rheum Dis 2007 [Epub ahead of print].

28. Schiff M, Keiserman M, Codding C, Songcharoen S, Berman A, Nayiager S, Saldate C, Li T, Aranda R, Becker J-C , Lin C, Cornet PLN, Dougados M: Efficacy and safety of abatacept or infliximab vs placebo in ATTEST: a phase III, multi-centre, randomised, double-blind, placebo-controlled study in patients with rheumatoid arthritis and an inadequate response to methotrexate. Ann Rheum Dis 2008, 67:1096-1103.

29. Genovese MC, Becker JC, Schiff M, Luggen M, Sherrer Y, Kremer J, Birbara C, Box J, Natarajan K, Nuamah I, Li T, Aranda R, Hagerty DT, Dougados M: Abatacept for rheumatoid arthritis refractory to tumor necrosis factor alpha inhibition. N Engl J Med 2005, 353:1114-1123.

30. Genovese MC, Schiff M, Luggen M, Becker JC, Aranda R, Teng J, Li T, Schmidely N, Le Bars M, Dougados M: Efficacy and safety of the selective co-stimulation modulator abatacept following 2 years of treatment in patients with rheumatoid arthritis and an inadequate response to anti-TNF therapy. Ann Rheum Dis 2008, 67:547-554.

31. Weinblatt M, Schiff M, Goldman A, Kremer J, Luggen M, Li T, Chen D, Becker JC: Selective costimulation modulation using abatacept in patients with active rheumatoid arthritis while receiving etanercept: a randomised clinical trial. Ann Rheum Dis 2007, 66:228-234.

32. Russell AS, Wallenstein GV, Li T, Martin MC, Maclean R, Blaisdell B, Gajia K, Cole JC, Becker JC, Emery P: Abatacept improves both the physical and mental health of patients with rheumatoid arthritis who have inadequate response to methotrexate treatment. Ann Rheum Dis 2007, 66:189-194.

33. Westhovens R, Cole JC, Li T, Martin M, Maclean R, Lin P, Blaisdell B, Wallenstein GV, Aranda R, Sherrer Y: Improved healthrelated quality of life for rheumatoid arthritis patients treated with abatacept who have inadequate response to anti-TNF therapy in a double-blind, placebo-controlled, multicentre randomized clinical trial. Rheumatology 2006, 45:1238-1246.

34. Weinblatt M, Combe B, Covucci A, Aranda R, Becker JC, Keystone E: Safety of the selective costimulation modulator abatacept in rheumatoid arthritis patients receiving background biologic and nonbiologic disease-modifying antirheumatic drugs: a one-year randomized, placebo-controlled study. Arthritis Rheum 2006, 54:2807-2816.

35. Hyrich KL, Silman AJ, Watson KD, Symmons DP: Anti-tumour necrosis factor alpha therapy in rheumatoid arthritis: an update on safety. Ann Rheum Dis 2004, 63:1538-1543.

36. Dass S, Vital EM, Emery P: Development of psoriasis after B cell depletion with rituximab. Arthritis Rheum 2007, 56:27152718.

37. Haggerty HG, Abbott MA, Reilly TP, DeVona DA, Gleason CR, Tay L, Dodge R, Aranda R: Evaluation of immunogenicity of the $T$ cell costimulation modulator abatacept in patients treated for rheumatoid arthritis. J Rheumato/ 2007, 34:2365-2373.

38. Sibilia J, Westhovens R: Safety of T-cell co-stimulation modulation with abatacept in patients with rheumatoid arthritis. Clin Exp Rheumatol 2007, 25(suppl 46):S46-S56.

39. Judge TA, Tang A, Spain LM, Deans-Gratiot J, Sayegh MH, Turka LA: The in vivo mechanism of action of CTLA4lg. J Immunol 1996, 156:2294-2299.

40. Fontenot AP, Gharavi L, Bennett SR, Canavera SJ, Newman LS, Kotzin BL: CD28 costimulation independence of target organ versus circulating memory antigen-specific CD4 ${ }^{+} \mathrm{T}$ cells. J Clin Invest 2003, 112:776-784

41. Shimoyama Y, Nagafuchi H, Suzuki N, Ochi T, Sakane T: Synovium infiltrating $\mathrm{T}$ cells induce excessive synovial cell function through CD28/B7 pathway in patients with rheumatoid arthritis. J Rheumatol 1999, 26:2094-2101.

42. Weisman $M H$, Durez $P$, Hallegua $D$, Aranda $R$, Becker JC, Nuamah I, Vratsanos G, Zhou Y, Moreland LW: Reduction of inflammatory biomarker response by abatacept in treatment of rheumatoid arthritis. J Rheumato/ 2006, 33:2162-2166.

43. Davis PM, Nadler SG, Stetsko DK, Suchard SJ: Abatacept modulates human dendritic cell-stimulated T-cell proliferation and effector function independent of IDO induction. Clin Immunol 2008, 126:38-47.

44. Buch $M H$, Boyle D, Saleem B, Rosengren $S$, Reece R, Rhodes $L$ Radjenovic A, English A, Tang $H$, Vratsanos G, O'Connor $P$, Firestein GS, Emery P: Mode of action of abatacept in rheuma- toid arthritis patients having failed TNF blockade: a histological, gene expression and dynamic MRI study. Arthritis Rheum 2005, 52:S1164.

45. Tak PP, Taylor PC, Breedveld FC, Smeets TJ, Daha MR, Kluin PM, Meinders AE, Maini RN: Decrease in cellularity and expression of adhesion molecules by anti-tumor necrosis factor alpha monoclonal antibody treatment in patients with rheumatoid arthritis. Arthritis Rheum 1996, 39:1077-1081.

46. Smeets TJ, Kraan MC, van Loon ME, Tak PP: Tumor necrosis factor alpha blockade reduces the synovial cell infiltrate early after initiation of treatment, but apparently not by induction of apoptosis in synovial tissue. Arthritis Rheum 2003, 48:21552162.

47. Buch $\mathrm{MH}$, Bingham SJ, Seto $\mathrm{Y}$, McGonagle D, Bejarano V, White $J$, Emery P: Lack of response to anakinra in rheumatoid arthritis following failure of tumor necrosis factor alpha blockade. Arthritis Rheum 2004, 50:725-728.

48. Davidson A, Diamond B, Wofsy D, Daikh D: Block and tackle: CTLA4Ig takes on lupus. Lupus 2005, 14:197-203.

49. Vincenti F, Larsen C, Durrbach A, Wekerle T, Nashan B, Blancho G, Lang P, Grinyo J, Halloran PF, Solez K, Hagerty D, Levy E, Zhou W, Natarajan K, Charpentier B; Belatacept Study Group: Costimulation blockade with belatacept in renal transplantation. N Engl J Med 2005, 353:770-781. 